Research Article

\title{
Seismic Response Analysis of Pier considering Durability Damage Repair
}

\author{
Yan Liang $\mathbb{D},{ }^{1}$ Liangliang Li, ${ }^{1}$ Ruimin Mao, ${ }^{2}$ and Xiaoye Shi ${ }^{1}$ \\ ${ }^{1}$ School of Civil Engineering, Zhengzhou University, Zhengzhou 450001, China \\ ${ }^{2}$ Bridge Design Institute, Henan Provincial Transportation Planning Survey and Design Institute, Zhengzhou 450001, China
}

Correspondence should be addressed to Yan Liang; liangyan@zzu.edu.cn

Received 11 January 2020; Revised 9 June 2020; Accepted 4 July 2020; Published 22 July 2020

Academic Editor: Yann Malecot

Copyright (c) 2020 Yan Liang et al. This is an open access article distributed under the Creative Commons Attribution License, which permits unrestricted use, distribution, and reproduction in any medium, provided the original work is properly cited.

At present, most of the research studies on the seismic performance of the durability degraded reinforced concrete structure only consider the influence of a single factor. This paper comprehensively considers the factors such as concrete carbonization, steel corrosion, and bond slip performance degradation caused by other durability factors and durability damage repair and studies the influence of the above factors on the seismic performance of bridge structures. Based on the finite element model considering the bond slip and the material parameters of time-varying durability damage, the seismic performance analysis model of the pier is established considering material durability damage repair in different service periods. Then, the effect of material durability damage repair on the seismic performance of the pier is examined. The results show that the displacement of the pier top increases, the curvature of the pier bottom decreases, and the moment-curvature curve pinching phenomenon is further evident when considering the bond slip. When considering the durability damage repair of materials, the curvature considerably decreases (the maximum value is approximately 16.04\%) with the extension of the service time of the bridge, and the pier damage is substantially reduced.

\section{Introduction}

In recent years, the durability of existing bridges has become a research hotspot. With the extension of the service time of concrete bridges, concrete is carbonated by the influence of the surrounding air. The change in the chemical composition of the pore solution weakens the passivation and protection of steel bars. Subsequently, steel bars are corroded by the influence of the surrounding chloride ions. Corrosion of steel bars in concrete reduces the diameter, strength, and elasticity modulus of steel bars, cracks, or even exfoliates concrete cover. It weakens the bond between steel bars and concrete [1-3].

Most of the offshore bridges are under the conditions of the marine environment and warm climate. The high chloride ion concentration in air leads to serious corrosion of steel bars and the reduction of bond stress between steel bars and concrete. Consequently, such phenomenon reduces the bearing capacity and durability of bridges and seriously affects the safety and seismic performance of bridge structures in the entire life cycle. Therefore, the damage evolution law of concrete bridges in an offshore environment must be investigated, and the seismic response of concrete bridges under earthquake must be analysed.

At present, scholars at home and abroad have done a lot of research on carbonation of concrete (influencing factors of carbonization and the prediction models of carbonization depth [4-6]) and prediction model of steel corrosion rate [7-13]. Theoretical analysis [14] and experimental research [15-17] have been performed on the seismic performance of reinforced concrete structures after durability damage. However, research on the seismic performance [18] of durable degraded reinforced concrete structures [19] mostly considers the single factor of steel corrosion or concrete carbonization. It disregards the coupling effects of concrete carbonization, steel corrosion, degradation of bond slip, and durable damage repair on seismic performance. Therefore, based on the OpenSees platform, a finite element analysis 
model considering the factors of concrete carbonation, reinforcement corrosion, bond slip degradation, and material durability damage repair is established during the service life of the bridge. The influence of the above factors on the seismic performance of the structure or components under the offshore atmospheric environment is studied.

\section{Brief Introduction to the Project}

In this study, the Y2 pier of a $6 \times 60 \mathrm{~m}$ offshore large-span continuous beam bridge is used as the research object. The pier adopts C50 concrete; HRB335 as longitudinal reinforcement, with $32 \mathrm{~mm}$ diameter; and R235 as stirrup with $16 \mathrm{~mm}$ diameter. The pier is $36.4 \mathrm{~m}$ high, the cross section is hexagonal, the axial compression ratio is 0.197 , and the thickness of the concrete cover is $9 \mathrm{~cm}$. The geological condition of the bridge site is good. The bottom of the pier is a $1.5 \mathrm{~m}$ thick expanded foundation, and the top is consolidated with the beam body. The surrounding rock is weak weathered rock. The base material is C25 concrete. The site conditions of the bridge are as follows: 7-degree seismic fortification intensity of the first group and the second-class site. The stress state of concrete has a certain effect on its strength [20]. Considering the influence of stirrups on the concrete in the core area, the pier concrete section is divided into constraint and protective concretes on the basis of Mander's model. Figure 1 is a detailed view of the bridge.

\section{The Finite Element Analysis Model}

3.1. Definition of the Model. A concrete01 constitutive model is adopted for the concrete material of the pier. Concrete 01 is based on the uniaxial compressive stress-strain relationship of Kent-Scott-Park concrete with linear unloading/ reloading stiffness, which ignores the tensile strength of concrete.

Steel02 constitutive model is used for longitudinal reinforcement. Steel02 material model is a uniaxial isotropic Giuffre-Menegotto-Pinto model [21], which can efficiently simulate the nonlinear behaviour of reinforcement under seismic load, including the degradation of strength and stiffness. The skeleton curve is a two-line model. The Bond_SP01 constitutive model in OpenSees material library is used for the bonded slip material.

In OpenSees software simulation, the pier body is divided into 37 nonlinear beam-column elements, each of which has three integral control points. The lengths of units 1 to 36 and 37 are 1 and $0.44 \mathrm{~m}$, respectively. The expanded foundation at the pier bottom is consolidated directly without considering the interaction between pile and soil. The zero-length section element is used to simulate the corner and displacement deformations caused by bond slip at the pier bottom. The consolidation between the top and beam is simplified as a zero-length element. Node $i$ represents the pier top, and node $j$ represents the contact point between the pier and beam and is consolidated. As the pier section is not shaped like a regular rectangle or fan, the concrete should be divided in a quadrilateral. Figure 1 presents the bridge details and specific sectional fibre division of the bridge pier.

3.2. Ground Motion Inputting. When the time-history analysis method is used to analyse the seismic response of the bridge structure, the reasonable selection of seismic wave is the premise of the seismic analysis. To ensure the reliability of calculation results, an appropriate seismic wave must be selected in combination with site conditions of the bridge.

Seismic parameters are the bases of seismic design. Different bridges have various requirements for seismic safety evaluation, which are mainly determined by bridge type and safety, risk, and social impact. Based on the zoning map of ground motion parameters and site conditions (seismic fortification intensity of 7 degrees, group I, and class II site) of bridge piers in China, ten seismic waves with a magnitude of about 7 are selected from the existing strong earthquake records [22] for incremental dynamic analysis. The selected types should be the same as the site conditions of the research bridge, and their characteristic periods should be close or the same [23-25].

Peak ground acceleration (PGA) [26-30] is used as the index of ground motion intensity. As the selected PGA of seismic wave is different from the required PGA, the amplitude of the selected PGA should be adjusted using the following equation:

$$
a^{\prime}(t)=\frac{A^{\prime}}{A} a(t)
$$

where $a^{\prime}(t)$ and $a(t)$ are time-history curves of the acceleration of seismic wave after and before amplitude modulation, respectively, and $A^{\prime}$ and $A$ are peak accelerations of seismic wave after and before amplitude modulation, respectively.

Based on the bridge site conditions, the PGA of the seven-degree fortification design ground motion is $0.1 \mathrm{~g}$ $(0.15 \mathrm{~g})$, corresponding to the PGA of ground motion whose exceeding probability is $10 \%$ in 50 years. To simulate the earthquake that the pier may encounter, the selected seismic wave should be adjusted in the calculation model such that the vertical and horizontal peak accelerations can satisfy the requirements of E2 seismic action of 0.3 and $0.6 \mathrm{~g}$, respectively. Table 1 shows the adjustment of horizontal and vertical ground motions.

\section{Research on Mechanical Properties of Materials}

4.1. Study on the Properties of Carbonized Concrete. Given that the bridge structure requires high ductility of the pier, the arrangement of stirrups can effectively restrain core concrete and improve the strength and ductility of concrete in the core area. The restraint effect of stirrups should be simulated during finite element modelling. The coefficient of constrained effect is considered on the basis of Mander's constitutive model [31] of constrained concrete. The restraint effect of stirrups on the core concrete is equivalent to the effective uniform lateral pressure. The stress-strain 


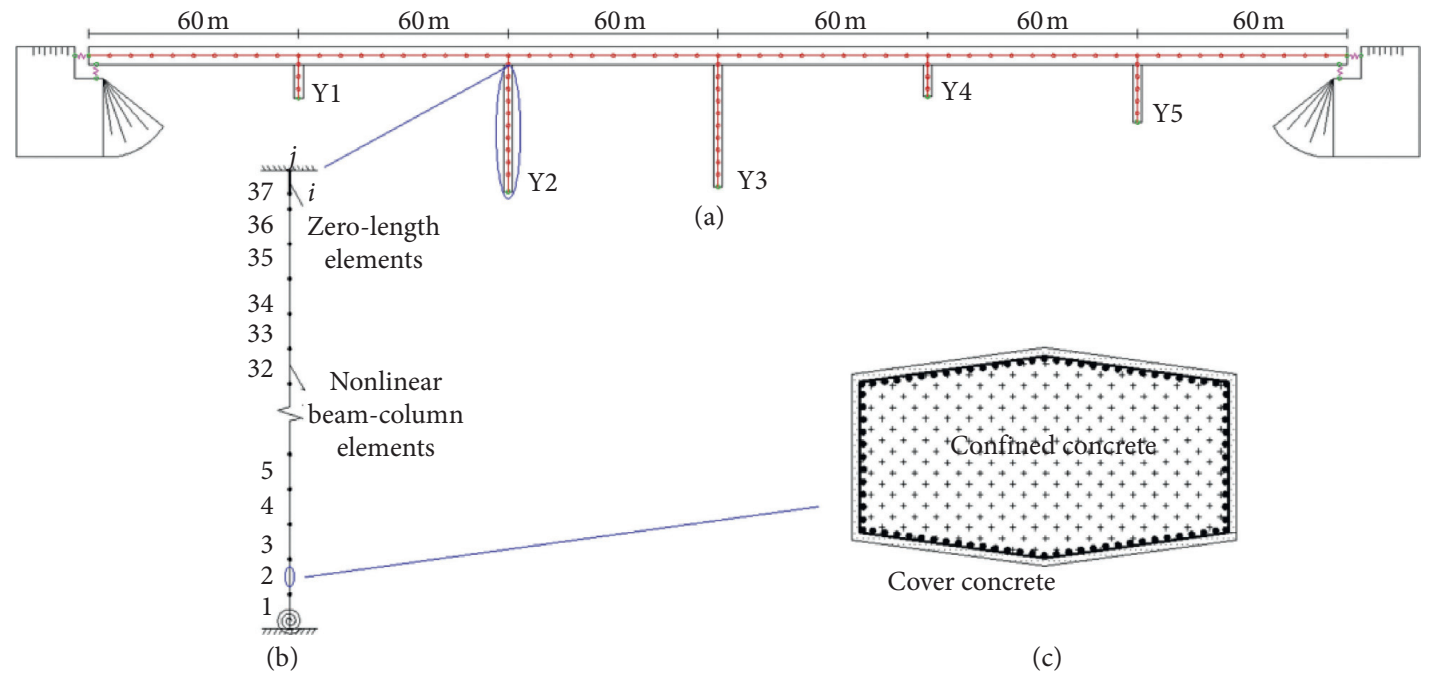

FIgURE 1: The bridge details: (a) bridge schematic; (b) the simplified model of bridge pier; (c) pier cross section.

TABLE 1: Horizontal and vertical time-history analysis of seismic wave adjustment.

\begin{tabular}{lcccc}
\hline Seismic wave & Magnitude & PGA (g) & $\begin{array}{c}\text { Adjustment coefficient of PGA } \\
(0.3 \mathrm{~g})\end{array}$ & $\begin{array}{c}\text { Adjustment coefficient of PGA } \\
(0.6 \mathrm{~g})\end{array}$ \\
\hline Loma Prieta, America, 1989 & 6.93 & 0.076 & 3.95 & 7.89 \\
Northridge 01, America, 1994 & 6.69 & 0.35 & 0.86 & 1.71 \\
Cape Mendocino, America, 1992 & 7.01 & 0.19 & 1.58 & 3.16 \\
Landers, America, 1992 & 7.28 & 0.04 & 7.50 & 15.00 \\
Hector Mine, America, 1999 & 7.13 & 0.05 & 6.00 & 12.00 \\
Coalinga 01, America, 1983 & 6.36 & 0.12 & 2.50 & 5.00 \\
Taiwan SMART1 (45), Taiwan, China, & 7.3 & 0.16 & 1.88 & 3.75 \\
1986 & 7.62 & 0.06 & 5.00 & 10.00 \\
Chi-Chi, Taiwan, China, 1999 & 7.14 & 0.01 & 30.00 & 60.00 \\
Duzce, Turkey, 1999 & 7.51 & 0.31 & 0.97 & 1.94 \\
Kocaeli, Turkey, 1999 & & & & \\
\hline
\end{tabular}

constitutive relationship curve of the core concrete is modified, which can effectively evaluate the ultimate bearing capacity and ductility of bridge structures.

The stochastic process model of concrete carbonation depth is as follows [32]:

$$
\begin{aligned}
X(t) & =k \sqrt{t}, \\
k & =3 K_{c o 2} K_{k 1} K_{k 2} K_{k 3} K_{F} T^{1 / 4} R H^{1.5}(1-R H)\left(\frac{58}{f_{\text {cuk }}}-0.76\right), \\
K_{F} & =1.0+13.34 F^{0.3},
\end{aligned}
$$

where $X(t)$ is the depth of concrete carbonization, $t$ is the time of carbonization, $K$ is the coefficient of carbonization, $K_{c o 2}$ is the coefficient of influence of $\mathrm{CO}_{2}$ concentration, and $K_{k 1}$ is the influence coefficient of position. The angle part is 1.4 , and the nonangle part is 1.0. $K_{k 2}$ is the coefficient of influence of curing and pouring, and 1.13 is the coefficient of influence of pouring surface. $K_{k 3}$ is the coefficient of influence of working stress, 1.0 is the coefficient of influence by compression, and 1.2 is the coefficient of influence by tension. $T$ is the concrete temperature, $R H$ is the relative humidity of the environment, $K_{F}$ is the replacement coefficient of fly ash, $f_{\text {cuk }}$ is the cubic compressive strength of concrete, and $F$ is the weight ratio of fly ash.

Based on the bridge design, construction, and site selection in this paper, $K_{c o 2}=1.2, \quad K_{k 1}=1.0$, $K_{k 2}=1.2, K_{k 3}=1.0, T=16.5^{\circ} \mathrm{C}, R H=77 \%$, and $F=0$. From this, we can get the carbonization coefficient of C50 concrete, $k=0.541 \mathrm{~mm} / \sqrt{a}$.

Existing research results [33] indicate that the concrete carbonization rate often uses the carbonization depth as a parameter. However, the same carbonization depth in the structure or component of different crosssectional areas has a great influence on the structural properties. The environment with different surfaces of the same structure after carbonization is not the same. The use of carbonization depth as parameter ignores the cross-sectional size effect and environmental impact of the actual component. To consider the size effect of component sections and reasonably reflect the evolution law of mechanical properties of concrete after 
carbonization, the relative carbonization area [34] of the concrete section is selected as the parameter to study the performance of carbonized concrete.

The carbonation rate of concrete can be calculated using the following equation:

$$
\bar{S}=\frac{A_{c}}{A},
$$

where $S$ is the relative carbonization area, $A_{c}$ is the carbonization area, and $A$ is the total area of the structure or component section.

According to the above formula, when the service life is $0,30,50,70,100$, and 120 years, the carbonation depth of the pier is $0,2.96,3.83,4.53,5.41$, and $5.93 \mathrm{~mm}$, respectively, and the carbonation rate of the corresponding cover concrete is $0,0.39 \%, 0.50 \%, 0.59 \%, 0.71 \%$, and $0.78 \%$, respectively. Table 2 shows the elastic modulus and shear modulus of C50 in different service periods.

4.2. Study on the Properties of Corroded Steel Bars. In offshore environments, reinforced concrete structures are susceptible to corrosion damage because of high chloride content. The corrosion damage process can be divided into three stages [35]: diffusion, propagation, and degradation. The ductility and yield strength of reinforcement will degenerate with the decrease in reinforcement area, and the internal expansion of the structure caused by corrosion will result in the cracking of concrete materials, leading to the spalling of concrete cover. In the past, when evaluating the seismic performance of degraded bridge structures, cracks caused by steel corrosion are often repaired in practical projects. Hence, the corrosion rate of the important index in steel corrosion analysis becomes relatively different from the actual situation. Before studying the corrosion of steel bars in concrete bridge structures in the offshore environment, it is necessary to consider the repair problem when the crack width of the cover concrete reaches a critical value.

Fick's second diffusion law [36] is often used to fit the process of steel bar corrosion affected by air composition in an offshore environment. Wu et al. [37] stated that the related parameters will change with variations in time and the air environment, such as the initial time of steel corrosion $\left(t_{\text {init }}\right)$, the chloride ion concentration on the concrete surface $\left(C_{s}\right)$, and the critical chloride ion concentration on steel corrosion $\left(C_{c r}\right)$. To some extent, these parameters can be regarded as random variables obeying normal distribution.

According to the calculation models of $\mathrm{Vu}$ and Stewart [38] and Du et al. [39], we can get the change law of steel bar diameter, steel bar yield strength, and steel bar corrosion rate with time: steel bar diameter and steel bar yield strength gradually decrease with time, and the steel bar corrosion rate gradually increases. As the stirrup protection layer is thinner, the mechanical properties of the reinforcement are more degraded. The characteristic values of steel bars in different service periods are shown in Table 3.

This paper refers to the "Standard for Durability Assessment of Concrete Structures" (CECS 220-2007) [40] to
TABLE 2: Elastic modulus and shear modulus of C50 in different service periods.

\begin{tabular}{lcccccc}
\hline Service life (years) & 0 & 30 & 50 & 70 & 100 & 120 \\
\hline $\begin{array}{l}\text { Elasticity modulus } \\
\left(\times 10^{4} \mathrm{MPa}\right)\end{array}$ & 3.450 & 3.457 & 3.458 & 3.460 & 3.462 & 3.463 \\
$\begin{array}{l}\text { Shear modulus } \\
\left(\times 10^{4} \mathrm{MPa}\right)\end{array}$ & 1.437 & 1.440 & 1.441 & 1.442 & 1.443 & 1.443 \\
\hline
\end{tabular}

estimate the variation law of steel corrosion under a chloride ion erosion environment. Without considering the change in chloride ion diffusion coefficient with time, the time of steel bar corrosion can be estimated using the following equations:

$$
\begin{aligned}
& t_{i}^{\prime}=\left(\frac{c}{K}\right)^{2} \times 10^{-6}, \\
& t_{i}=t_{i}^{\prime}+0.2 t_{1},
\end{aligned}
$$

where $t_{i}^{\prime}$ is the initial corrosion time of reinforcing steel without considering the chloride ion diffusion coefficient, $t_{i}$ is the initial corrosion time of reinforcing steel under offshore environment, $t_{1}$ is the accumulated time of chloride ion reaching a stable value on the concrete surface, $c$ is the thickness of the concrete cover, and $K$ is the chloride ion corrosion coefficient, and according to Table $4, t_{1}(a)$ is $\mathbf{1 2 . 5}$. The initial corrosion time of longitudinal reinforcement is 21.77 years and that of stirrups is 15.53 years.

In the absence of effective measured data, the chloride ion concentration $M_{s}$ on the surface of concrete in the offshore atmospheric environment can be estimated according to equation (6). It is assumed that the distance between the bridge structure to the coastline is $0.5 \mathrm{~km}$ :

$$
M_{s}=M_{s}^{\prime} k \text {, }
$$

where $M_{s}$ is the chloride ion concentration on the concrete surface, $M_{s}{ }^{\prime}$ is the chloride ion concentration on the concrete surface at $0.1 \mathrm{~km}$ away from the coast, as shown in Table 5 , and $k$ is the position correction factor for the distance from the coastline, as shown in Table 6 .

The variations in diameter, yield strength, elasticity modulus, and corrosion rate of steel bars can be obtained using the following equations:

$$
\begin{aligned}
& t_{c r}=t_{i}+t_{c}, \\
& t_{c}=\frac{\delta_{c r}}{\lambda_{c l}}, \\
& \delta_{c r}=\frac{0.012 c}{d}+0.00084 f_{c u k}+0.018 \\
& \lambda_{c l}=11.6 \times i \times 10^{-3}, \\
& \ln i=8.617+0.618 \ln M_{s l}-\frac{3034}{T+273}-5 \times 10^{-3} \rho+\ln m_{c l}, \\
& M_{s l}=M_{s 0}+\left(M_{s}-M_{s 0}\right)\left[1-\operatorname{erf}\left(\frac{c \times 10^{-3}}{2 \sqrt{D t_{c r}}}\right)\right]
\end{aligned}
$$


TABLE 3: The characteristic values of steel bars corresponding to different service periods.

\begin{tabular}{lccccc}
\hline Service life (years) & 0 & 30 & 50 & 70 & 100 \\
\hline Yield strength of stirrup (MPa) & 235 & 184.32 & 166.75 & 153.50 & 139.04 \\
Diameter of stirrup (mm) & 16 & 11.97 & 10.21 & 8.65 & 6.53 \\
Corrosion rate of stirrup (\%) & 0 & 14.87 & 40.01 & 56.35 & 73.54 \\
Yield strength of longitudinal bar (MPa) & 335 & 326.86 & 323.59 & 320.83 & 317.32 \\
Diameter of longitudinal bar (mm) & 32 & 28.58 & 27.08 & 25.75 & 81.82 \\
Corrosion rate of longitudinal bar (\%) & 0 & 0 & 13.38 & 22.99 & 315.28 \\
\hline
\end{tabular}

TABLE 4: Environmental grade and parameters of chloride erosion.

\begin{tabular}{lccc}
\hline Environmental category & Environmental grade & Environmental condition & $t_{1}(a)$ \\
\hline & IIIa & Within one kilometer from the coast & $20 \sim 30$ \\
Offshore atmospheric environment & IIIb & Within one kilometer from the coast & $15 \sim 20$ \\
& IIIc & Within one kilometer from the coast & $10 \sim 15$ \\
& IIId & Within one kilometer from the coast & 10 \\
\hline
\end{tabular}

TABLE 5: Chlorine ion concentration $M_{s}^{\prime}$ at $0.1 \mathrm{~km}$ from the coast.

\begin{tabular}{lllll}
\hline$f_{\text {cuk }}(\mathrm{MPa})$ & 40 & 30 & 25 & 20 \\
$M_{s}^{\prime}\left(\mathrm{kg} / \mathrm{m}^{3}\right)$ & 3.2 & 4.0 & 4.6 & 5.2 \\
\hline
\end{tabular}

TABLE 6: Correction coefficient $k$ of chloride ion concentration.

\begin{tabular}{lcccccc}
\hline $\begin{array}{l}\text { Distance from the coast } \\
(\mathrm{km})\end{array}$ & $\begin{array}{l}\text { Near the } \\
\text { coastline }\end{array}$ & 0.1 & 0.25 & 0.5 & 1.0 \\
\hline Correction factor & 1.96 & 1.0 & 0.66 & 0.44 & 0.33 \\
\hline
\end{tabular}

$$
\begin{aligned}
\rho & =k_{\rho}\left(1.8-M_{c l}^{u}\right)+10(R H-1)^{2}+4, \\
\lambda_{c l l} & =\left(4.5-26 \lambda_{c l}\right) \times \lambda_{c l} . \\
\text { When } \lambda_{c l l}<1.8 \lambda_{c l}, \lambda_{c l l}=1.8 \lambda_{c l}: & t \leq T_{i}, \\
d(t) & = \begin{cases}d_{0}, & \\
d_{0}-2 \lambda\left(t-T_{i}\right), & T_{i} \leq t \leq T_{c r}, \\
0, & t \geq T_{c r},\end{cases} \\
f_{y c} & =(1-0.339 \rho) f_{y}, \\
E_{x} & =(1-1.166 \rho) E_{s},
\end{aligned}
$$

where $t_{c}$ is the time from steel bar corrosion to concrete cracking, $\delta_{c r}$ is the depth of steel bar corrosion when the concrete cracks, $\lambda_{c l}$ is the average annual corrosion rate of steel bar before concrete cracking, $d$ is the diameter of the steel bar, $f_{\text {cuk }}$ is the standard value of the concrete cube compressive strength, $i$ is the corrosion current density of the steel bar, $M_{s l}$ is the chloride ion concentration on the surface of the steel bar, $T$ is the atmospheric environment temperature, $\rho$ is the concrete resistivity, $m_{c l}$ is the local environmental coefficient, $M_{s 0}$ is the chloride ion content added during concrete preparation, $K_{\rho}$ is the coefficient when the water cement ratio is $0.3-0.4$ or the concrete is C40-C50, $K$ is $11.1, M_{c l}^{u}$ is the average chloride ion concentration of the concrete cover, $R H$ is the environmental relative humidity, $\lambda_{c l l}$ is the average annual corrosion rate of the steel bar after concrete cracking, $f_{y c}$ is the yield strength of corroded steel bars, $f_{y}$ is the yield strength of steel bars before corrosion, $E_{x}$ is the elastic modulus of steel bars after corrosion, and $E_{s}$ is the elastic modulus of steel bars before corrosion.

The above two methods of calculating the corrosion rate both show that the initial corrosion time of stirrups is earlier than that of the longitudinal bars, and the corrosion rate of stirrups is much higher than that of the longitudinal bars after the cracking of the cover concrete. According to the calculation method proposed by $\mathrm{Vu}$ and $\mathrm{Du}$, the corrosion rate of cover concrete after cracking is higher than that calculated in the CECS 220-2007. There is a certain deviation between the two methods. The degradation process of the concrete structure under the environment is very complicated, and the various environmental factors are relatively random. The "CECS 220-2007" is compiled by accumulating a large amount of engineering practice data and engineering practice experience, which is more suitable for the application. Due to the research on the durability of concrete structures in China's offshore environment, this paper uses the calculation method of "CECS 220-2007" to study the durability of materials.

\section{Seismic Response Analysis of the Bridge Pier}

5.1. Seismic Response Analysis in Different Directions of Seismic Action. The pier model is established using OpenSees software [41]. The adjusted horizontal and vertical waves, which are divided into longitudinal, lateral, simultaneous longitudinal and lateral, simultaneous vertical and longitudinal, and simultaneous vertical and lateral actions, are input as ground motions. The displacement, moment, curvature, and axial force responses of the pier model are calculated. The influence of seismic wave in different directions on the seismic response of the pier is analysed.

Figure 2 shows the maximum displacement of the pier top corresponding to 10 waves in 5 different seismic action combinations. The graph indicates that, under longitudinal seismic action, the longitudinal peak displacement of the pier top is considerably larger than the transverse and vertical displacements. The maximum values of the longitudinal, transverse, and vertical displacements of the Landers wave pier top are 471.6, 0 , and $25.1 \mathrm{~mm}$, 


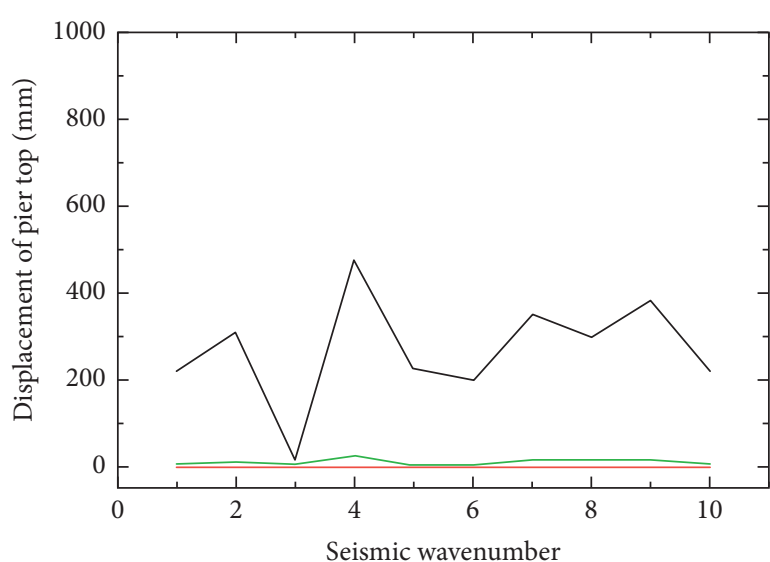

Longitudinal displacement

ransverse displacement

Vertical displacement

(a)

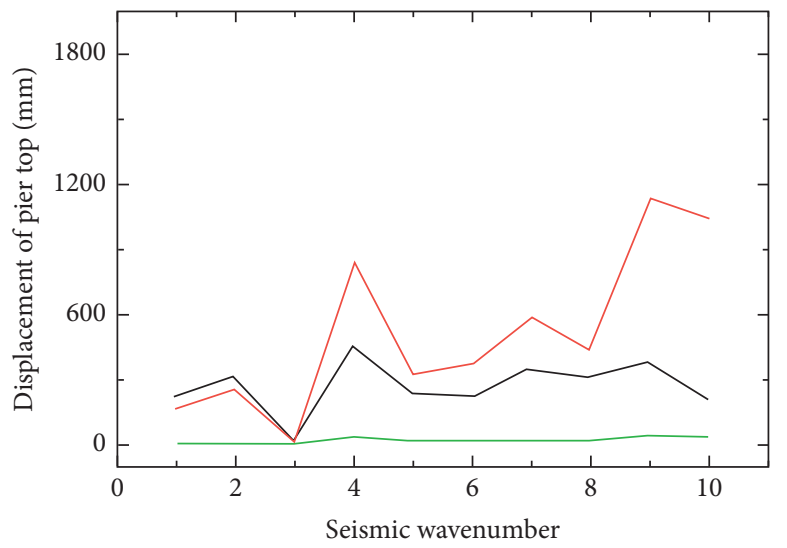

Longitudinal displacement

Transverse displacement

Vertical displacement

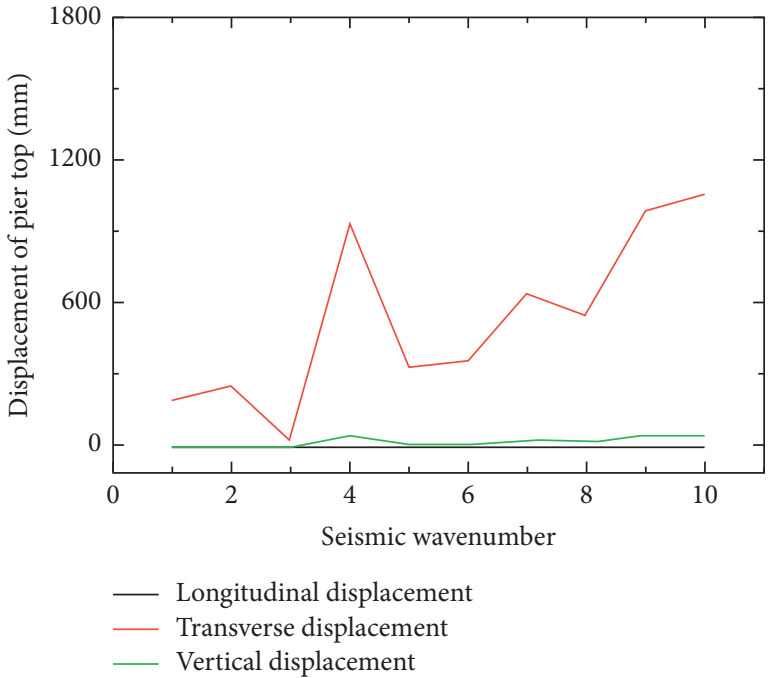

(b)

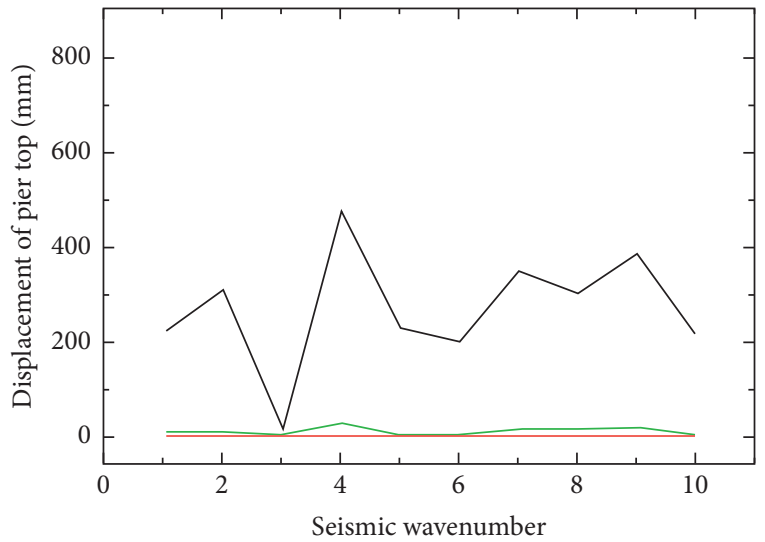

- Longitudinal displacement

_ Transverse displacement

__ Vertical displacement

(c)

(d)

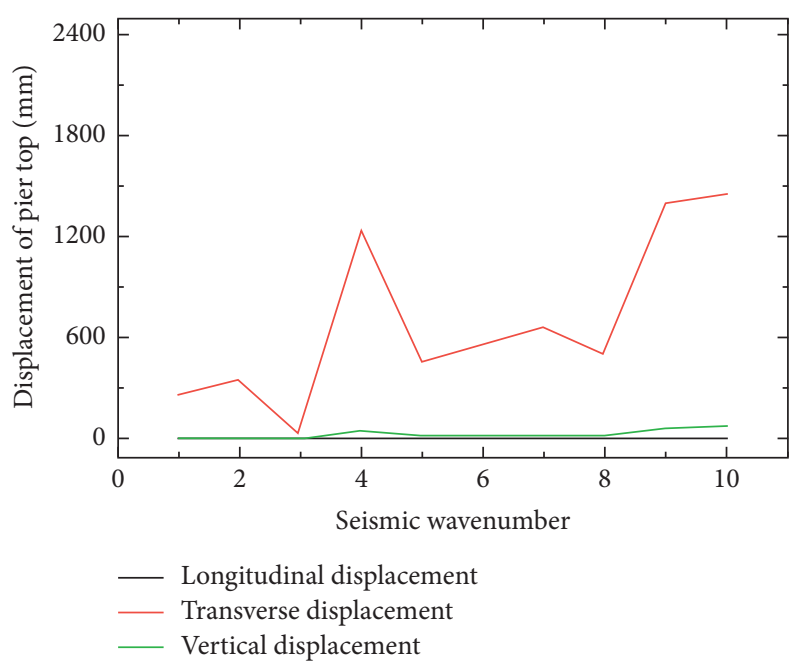

(e)

FIGURE 2: Maximum displacement of pier top under different seismic action combinations: (a) longitudinal action; (b) transverse action; (c) longitudinal and transverse simultaneous action; (d) longitudinal and vertical simultaneous action; (e) transverse and vertical simultaneous action. 
respectively. Under the effect of transverse earthquakes, the transverse peak displacement of the pier top is considerably larger than the longitudinal and vertical peak displacements. The maximum longitudinal, transverse, and vertical displacements of the pier top of the Landers wave are 0, 933.0, and $39.0 \mathrm{~mm}$, respectively. The direction of the main displacement of the pier is consistent with that of ground motion. Under the simultaneous action of longitudinal and transverse earthquakes, the maximum longitudinal, transverse, and vertical displacements of the pier top corresponding to the Landers wave are 463.8, 847.0, and $38.2 \mathrm{~mm}$, respectively. The transverse displacement of the pier top is considerably larger than the longitudinal and vertical displacements. The transverse seismic response of the high pier deserves attention due to the small transverse stiffness. Under the simultaneous action of longitudinal and vertical earthquakes, the maximum longitudinal and vertical displacements of the pier top corresponding to the Landers wave are 471.7 and $26.6 \mathrm{~mm}$, respectively. The maximum transverse and vertical displacements of the pier top corresponding to the Landers wave are 1245.1 and $55.1 \mathrm{~mm}$, respectively, under the simultaneous action of transverse and vertical earthquakes. Vertical seismic action significantly increases the vertical seismic response.

It can be obtained through analysis that the peak moment and curvature of the pier bottom under the action of the longitudinal earthquake and the simultaneous action of longitudinal and transverse earthquakes are larger than those under the simultaneous action of longitudinal and vertical earthquakes. The moment-curvature curves under these three types of ground motion are compared and analysed, and the other two are not discussed.

Figure 3 presents the moment-curvature curve of the pier bottom of 10 seismic waves. The analysis shows that the moment-curvature curve of the pier bottom is full under the simultaneous action of longitudinal and transverse earthquakes, and no remarkable pinching phenomenon was observed. The curvature value of the pier bottom is considerably increased compared with that of longitudinal earthquakes. The maximum curvature of the pier bottom under longitudinal earthquake is 0.029 and that under the simultaneous action of longitudinal and transverse earthquakes is 0.044 . Under the simultaneous action of vertical and longitudinal earthquakes and transverse and vertical earthquakes, the moment-curvature curve has no evident difference compared with the action of a longitudinal earthquake. The maximum value under the simultaneous action of vertical and longitudinal earthquakes is 0.030 . Under the action of transverse and vertical earthquakes, the maximum curvature value is 0.033 . It can be seen that the pier is most sensitive to longitudinal and transverse seismic waves.

Under longitudinal seismic action, the displacement of the pier top of the Landers wave is the largest among the ten seismic waves with a value of $471.6 \mathrm{~mm}$. Figures $4(\mathrm{a})$ and 4(b) show the displacement time-history curve of the pier top and the curvature time-history curve of the pier bottom under the Landers wave, respectively. Under the action of other seismic waves, the displacement time-history curve of the pier top and the curvature time-history curve of the pier bottom have the same law, which is not described here. The pictures show that, under the action of the Landers wave, the maximum displacement of the pier top and the maximum curvature of pier bottom occur at $33.78 \mathrm{~s}$. The fluctuation law of the two time-history curves is the same.

\section{Seismic Response Analysis considering Bond Slip}

Given the limited space, this paper only presents the effect of bond slip on the seismic response of the pier under the action of a longitudinal earthquake. In this paper, three waves are selected to analyse the displacement of the pier top and the moment-curvature curves at the bottom of the pier.

There are obvious differences in the three-pier top displacement time-history curves in Figure 5. Whether considering or not considering the bond slip, the maximum displacement of the pier top occurs at the same time. For the Northridge wave, the corresponding maximum displacements of the two models are 249.2 and $318.1 \mathrm{~mm}(27.6 \%$ increase). For the Taiwan wave, the corresponding maximum displacements of the two models are 281.6 and $354.4 \mathrm{~mm}$ (25.9\% increase). For the Duzce wave, the corresponding maximum displacements of the two models are 306.5 and $394.8 \mathrm{~mm}$ (28.8\% increase). In Figure 6 , the longitudinal peak displacements of 10 waves with the bond slip model are larger than those without the bond slip model and are increased by $26.8 \%, 27.6 \%, 14.7 \%, 27.4 \%, 29.3 \%$, $30.8 \%, 25.9 \%, 26.6 \%, 28.8 \%$, and $25.9 \%$, and the displacement is relatively different. The deformation of the pier top can be underestimated if the influence of bond slip at the pier bottom is ignored in the seismic calculation of the pier. Under the action of the longitudinal earthquake, the maximum displacement of the pier top is $480.7 \mathrm{~mm}$, the yield displacement of the pier is $276.6 \mathrm{~mm}$, and the ultimate displacement is $983.1 \mathrm{~mm}$. The pier has not reached the ultimate state, which indicates that the pier can still play a certain function under the action of a rare earthquake.

Figure 7 is the moment-curvature curve of the Northridge wave, the Taiwan wave, and the Duzce wave. Obviously, the curvature of the pier bottom considering the bond slip model is considerably smaller than that without considering the bond slip. For the Northridge wave, the peak curvatures before and after considering the bond slip are 0.0139 and 0.0106 (23.7\% decrease), respectively. The peak moments are 46776.1 and $46514.3 \mathrm{MPa}(0.6 \%$ decrease), respectively. For the Taiwan wave, the peak curvatures before and after considering the bond slip are 0.0189 and 0.0156 (17.5\% decrease), respectively. The peak moments are 46926.8 and $46178.7 \mathrm{MPa}$ (1.6\% decrease), respectively. For the Duzce wave, the peak curvatures before and after considering the bond slip are 0.0246 and 0.0219 (11.0\% decrease), respectively. The peak moments are 48720.2 and $48223.3 \mathrm{MPa}(1.0 \%$ decrease), respectively. The moment-curvature curve pinching phenomenon is further evident when considering the bond slip model of the pier. If the influence factors of the bond slip are 


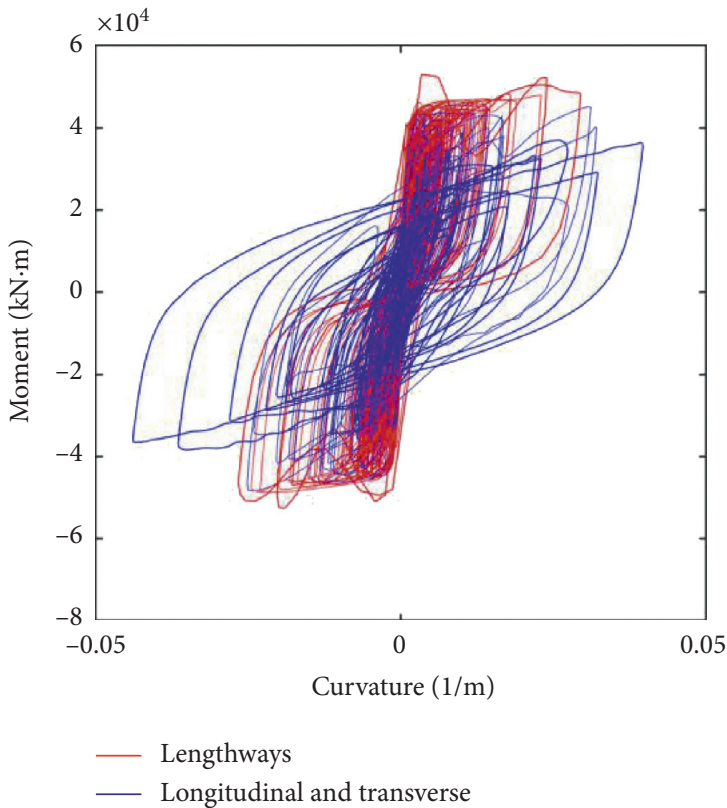

(a)

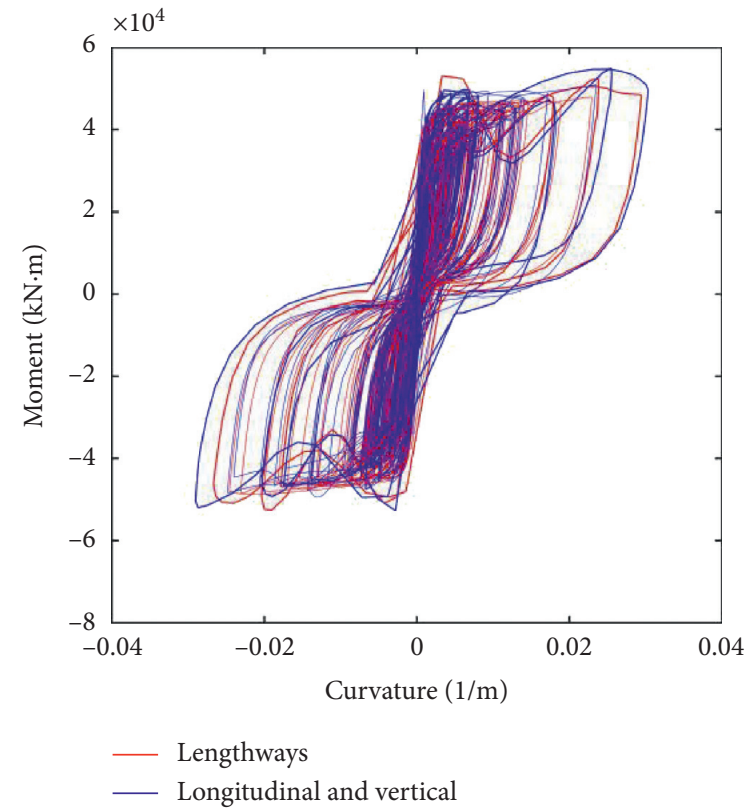

(b)

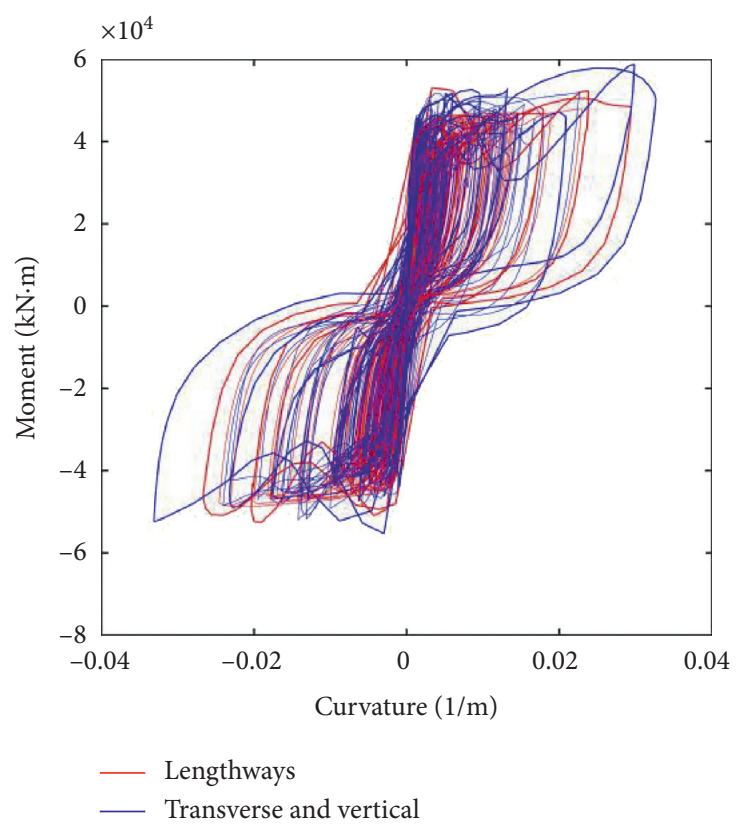

(c)

FIGURE 3: Moment-curvature curves of 10 waves at the pier bottom: (a) longitudinal and lateral simultaneous action; (b) vertical and longitudinal simultaneous action; (c) transverse and vertical simultaneous action.

neglected in the simulation calculation, the energy dissipation capacity of the structure or component will be overestimated.

\section{Seismic Response Analysis considering Durability Damage Repair}

In previous theoretical studies on steel corrosion, the repair of concrete cracks in the concrete cover is generally ignored in practical projects. The corrosion rate of steel after the concrete cover cracks is higher than the actual value, which affects the subsequent research results of concrete structures. The assumption is that, under the action of chloride ion erosion, the cracks of concrete cover will be repaired when they reach $1 \mathrm{~mm}$. After repair, the corrosion rate of steel bars in the pier will be the same as that before cracking. Vida et al. [42] obtained the calculation method of crack width by studying the corrosion of reinforced concrete structure as follows: 


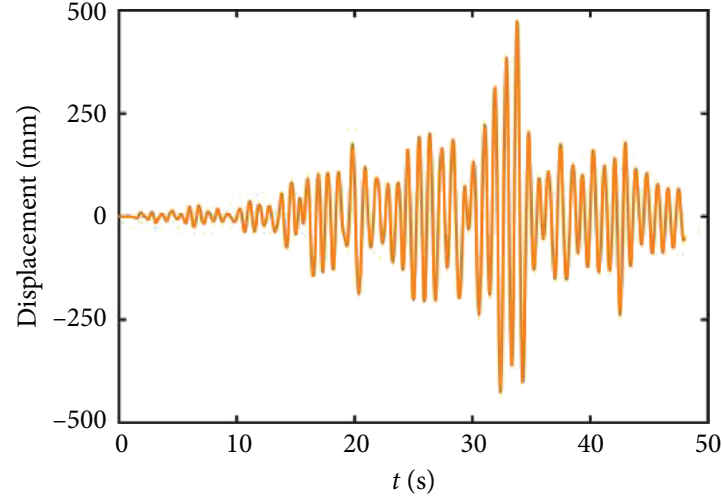

(a)

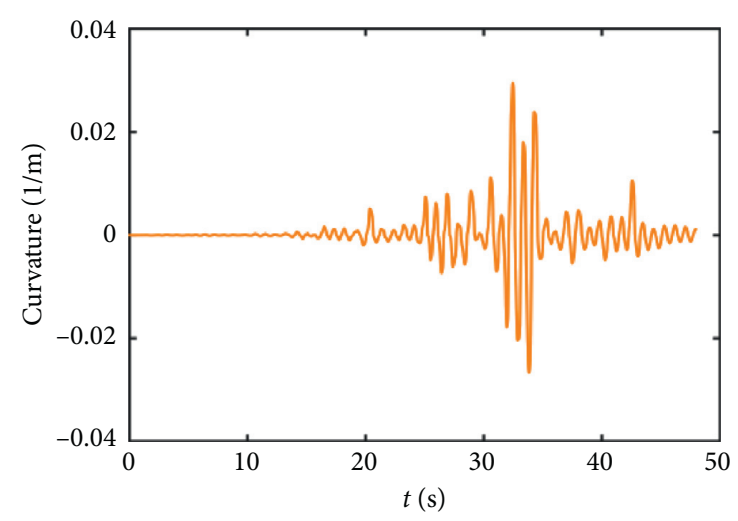

(b)

FIgURE 4: Time-history curve of displacement and curvature of the pier top of Landers wave: (a) displacement time-history curve; (b) curvature time-history curve.

$$
\begin{aligned}
w & =k\left(\Delta A_{s}-\Delta A_{s 0}\right), \\
\Delta A_{s} & =\frac{\pi}{4}\left(2 \alpha x_{\text {corr }} d_{s 0}-\alpha^{2} x_{\text {corr }}^{2}\right), \\
\Delta A_{s 0} & =A_{s}\left[1-\left[1-\frac{\alpha}{d_{s 0}}\left(7.53+9.32 \frac{X}{d_{s 0}}\right) \times 10^{-3}\right]^{2}\right],
\end{aligned}
$$

where $W$ is the crack width, $k$ is the coefficient with a value of 0.0575 , and $\alpha$ is the corrosion coefficient ( $\alpha=1$ for uniform rust and $\alpha=4$ for nonuniform rust). $d_{s 0}$ is the bar diameter, $X$ is the concrete cover depth, $\Delta A_{s 0}$ and $\Delta A_{s}$ are the steel crosssection losses, $A_{s}$ is the sound steel cross section, and $x_{\text {corr }}$ is the corrosion depth.

The influence of chloride ion on offshore bridges is random. Thus, the corrosion coefficient is 4. According to Vida's calculation method, the width of concrete cover from crack to crack is $1 \mathrm{~mm}$, which lasts for 0.759 years. According to the CECS 220-2007, the longitudinal steel bars begin rusting to crack the concrete cover. The average annual corrosion rate of steel bars is $0.015 \mathrm{~mm} /$ year. The average corrosion rate is $0.061 \mathrm{~mm} /$ year after concrete cover cracking. When the crack width reaches $1 \mathrm{~mm}$, the crack is repaired. The corrosion rate of repaired steel bars should be consistent with that before concrete cover cracking. Figure 8 shows the corrosion rate of steel bars considering crack repair. The corrosion rate of steel bars in the service period of the bridge decreases significantly when considering the repair. When the bridge is in service for 120 years, the corrosion rate of longitudinal steel bars decreases by $65.99 \%$, and the corrosion rate of stirrups decreases by $57.48 \%$. Hence, the effect of the crack repair of the concrete cover on the durability of concrete structures should be considered in future durability evaluations.

Based on the above calculation method, we can obtain the various rules of the diameter, yield strength, and elastic modulus of longitudinal stress bars with time when considering the crack repair of concrete cover. As shown in Figure 9, after considering the crack repair of concrete cover, the longitudinal reinforcement diameter, yield strength, and elastic modulus are considerably reduced. The bridge is in service for 120 years. The diameter, yield strength, and elastic modulus of longitudinal reinforcement decreases by $8.23 \%$, $5.08 \%$, and $18.66 \%$, respectively.

In the offshore environment, the corrosion of steel bars in the longitudinal direction will not directly affect the mechanical properties of confined concrete. However, the degradation of stirrup material will reduce its confinement to core concrete, which will change the peak stress and strain of confined concrete. The corresponding diameter and yield strength of stirrups can be calculated based on the corrosion rate of stirrups in different service periods. Subsequently, the peak stress, peak strain, and other mechanical properties of confined concrete can be calculated using Mander's model. The calculation basis and process are the same as above and will not be repeated here.

To study the effect of the crack repair of the concrete cover on the pier seismic response, the pier models with corresponding service lives of $0,30,50,70,100$, and 120 years were modified on the basis of the bond slip model and time-varying material parameters. The seismic actions are the same as above. The seismic response of pier under the Taiwan wave with different service lives is listed here.

Figure 10 shows the curvature time-history curve and moment-curvature curve corresponding to different service periods under Taiwan wave. It can be seen that, under the longitudinal action of Taiwan wave, the newly built bridge pier after 0 years of service is unaffected by the surrounding environment, and the structure is intact. The momentcurvature curve coincides completely with that without considering the damage repair model. When the bridge pier is in service for 30 years, the pier is subjected to concrete carbonization and chloride ion erosion for a relatively short time. The material is slightly damaged, and the structure remains intact. The two curves almost completely coincide. 


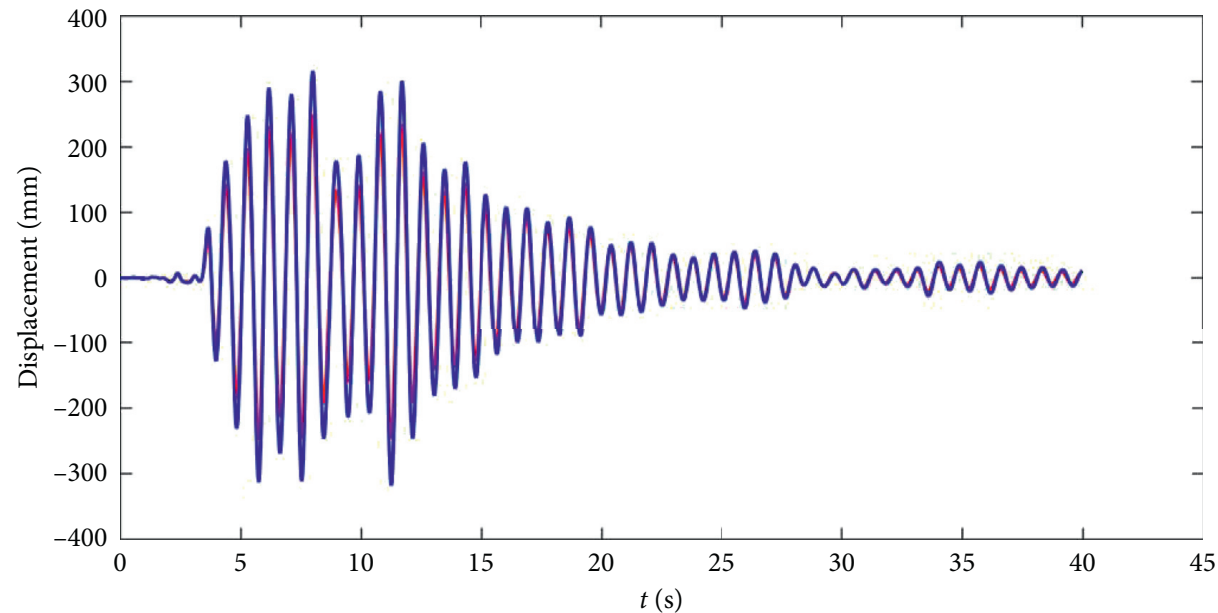

_ Bond slip is not considered Considering bond slip

(a)

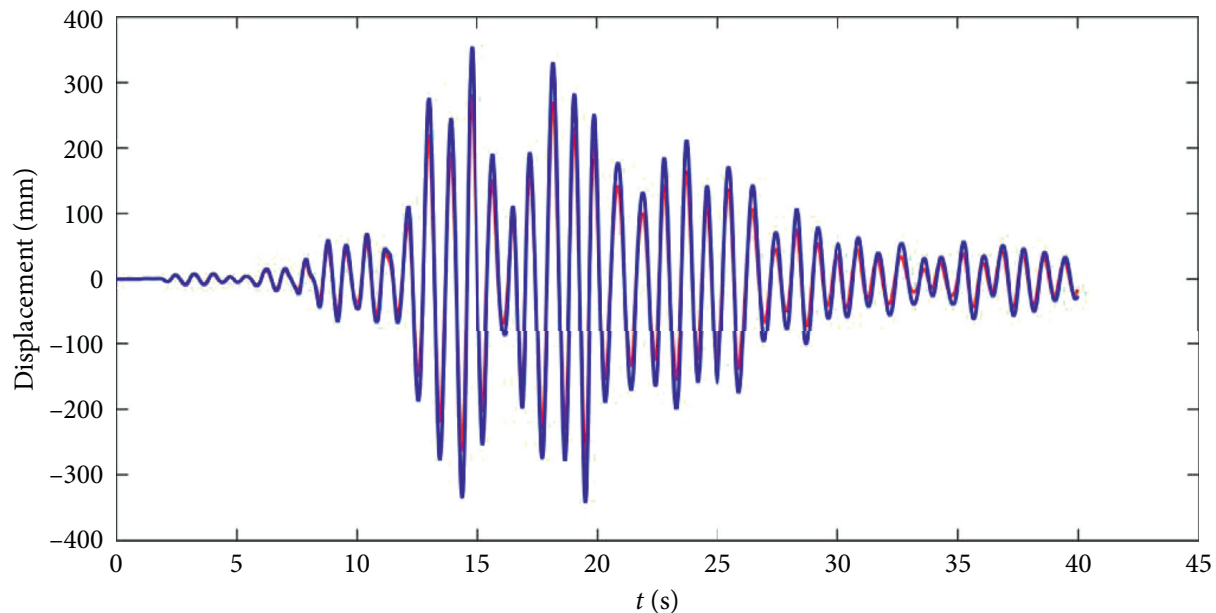

Bond slip is not considered

Considering bond slip

(b)

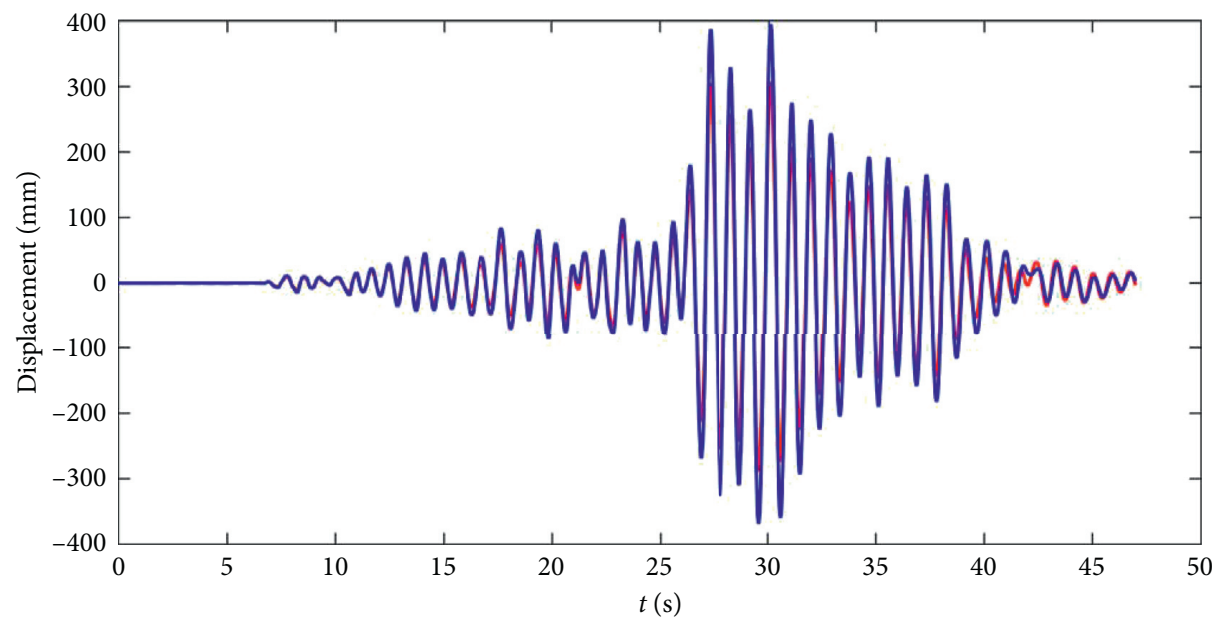

Bond slip is not considered

Considering bond slip

(c)

FIgURE 5: Displacement time-history curves of the pier top: (a) Northridge wave; (b) Taiwan wave; (c) Duzce wave. 


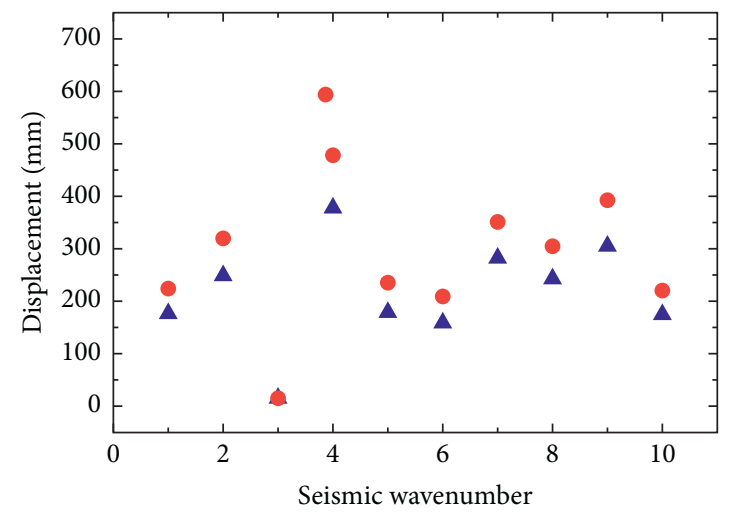

- Bond slip is not considered

- Considering bond slip

FIgURE 6: Longitudinal peak displacement of 10 waves.

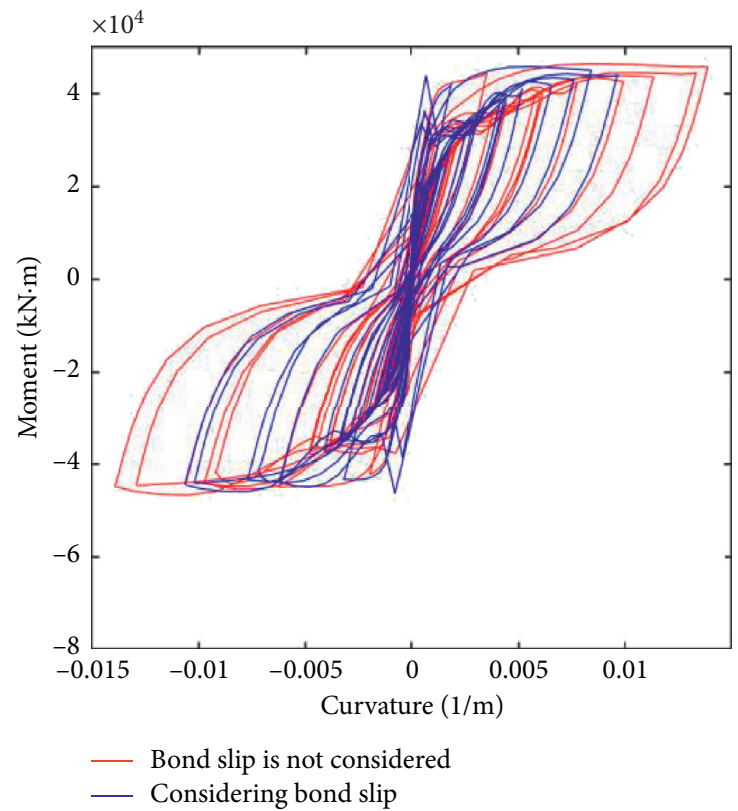

(a)

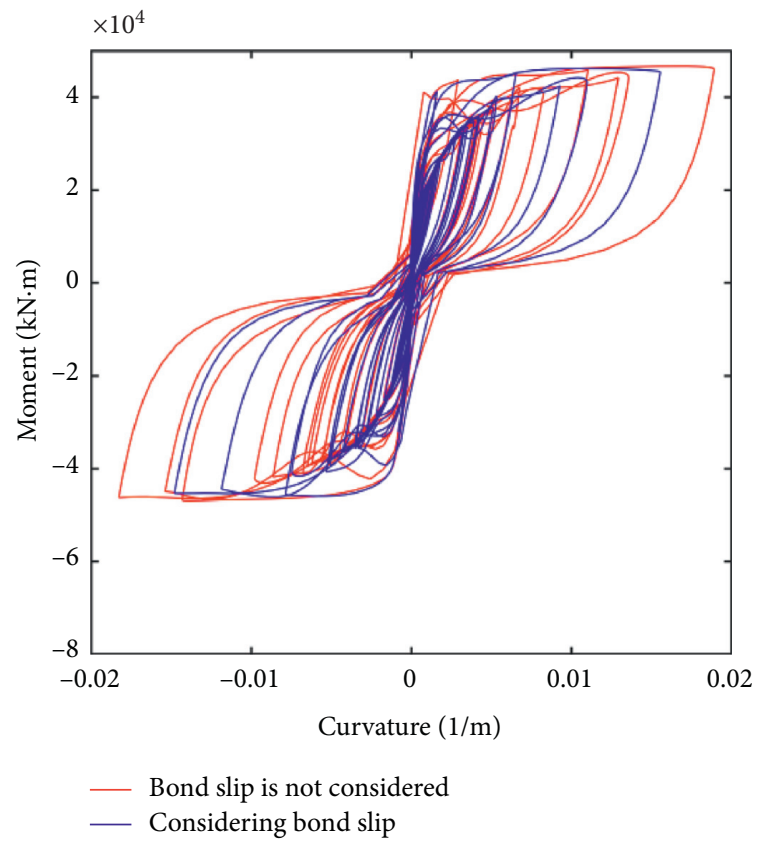

(b)

Figure 7: Continued. 


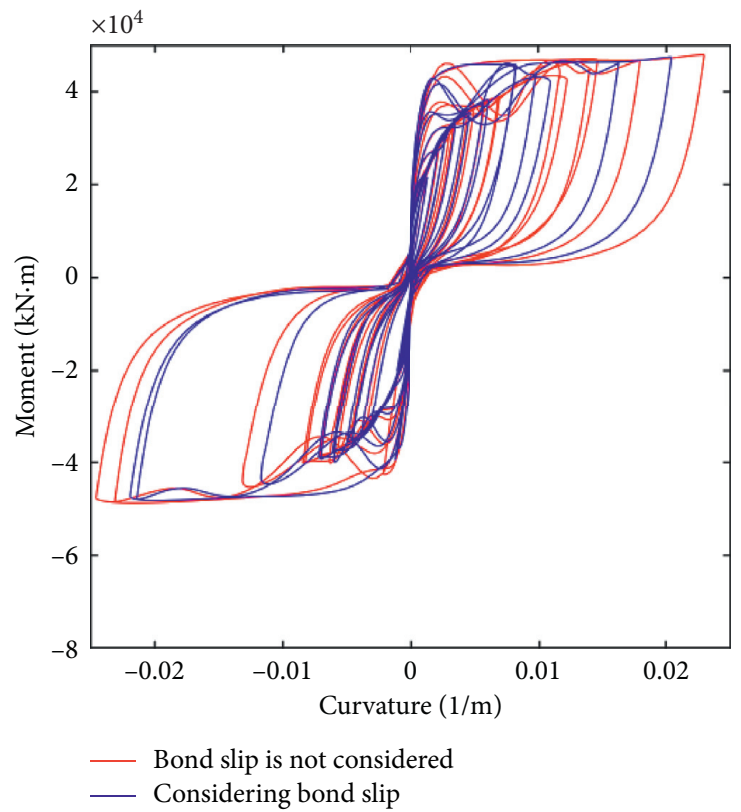

(c)

Figure 7: . Analysis of moment-curvature curves: (a) Northridge wave; (b) Taiwan wave; (c) Duzce wave.

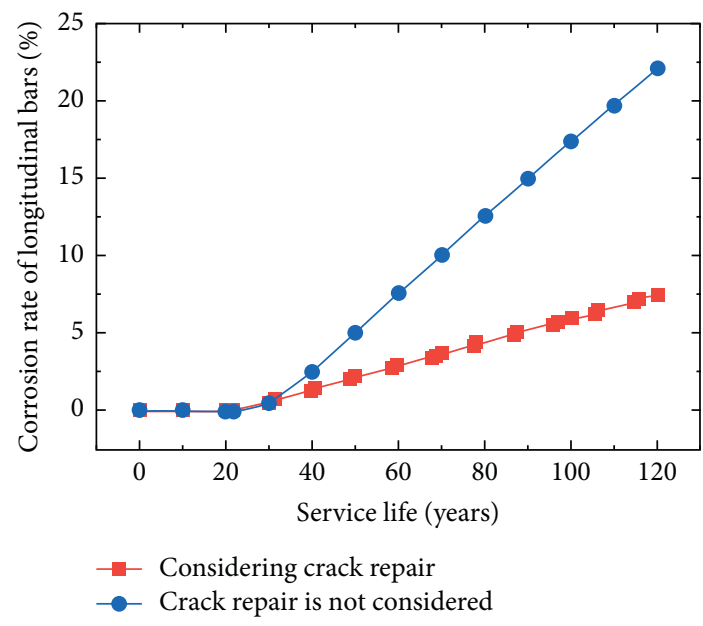

(a)

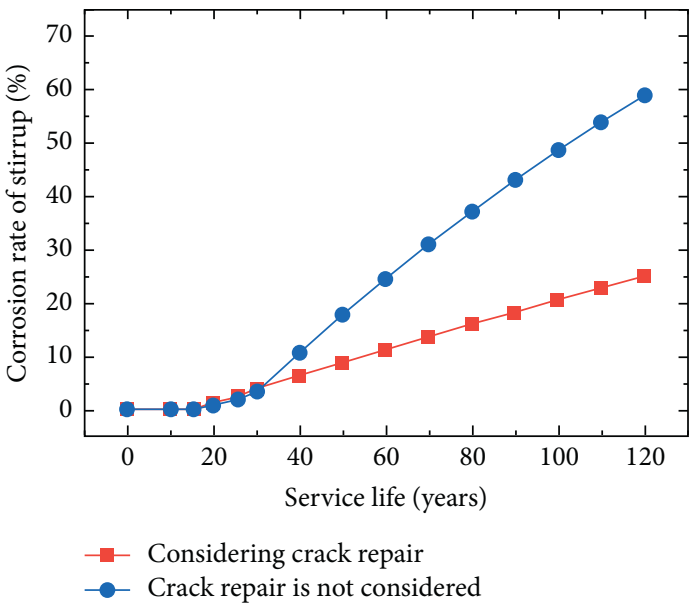

(b)

Figure 8: Corrosion rate of steel bars: (a) corrosion rate of longitudinal bars; (b) corrosion rate of stirrups.

When serving for 50 years, the pier is seriously damaged, and its structural performance is reduced. The maximum curvature of the bridge pier is reduced from 0.0162 to 0.0158 (2.2\% reduction) after considering repairing the damage. When serving for 70 years, pier is seriously damaged. The maximum curvature of the bridge pier is reduced from 0.017 to 0.016 (5.3\% reduction) after considering repairing the damage.
When serving for 100 years, the pier is seriously damaged. The maximum curvature of the bridge pier is reduced from 0.0185 to 0.0164 (11.3\% reduction) after considering repairing the damage. When serving for 120 years, the pier is seriously damaged due to the long-term marine environment. The maximum curvature is decreased from 0.024 to 0.020 ( $16.0 \%$ reduction) after considering damage repair, and the pier damage is considerable. 

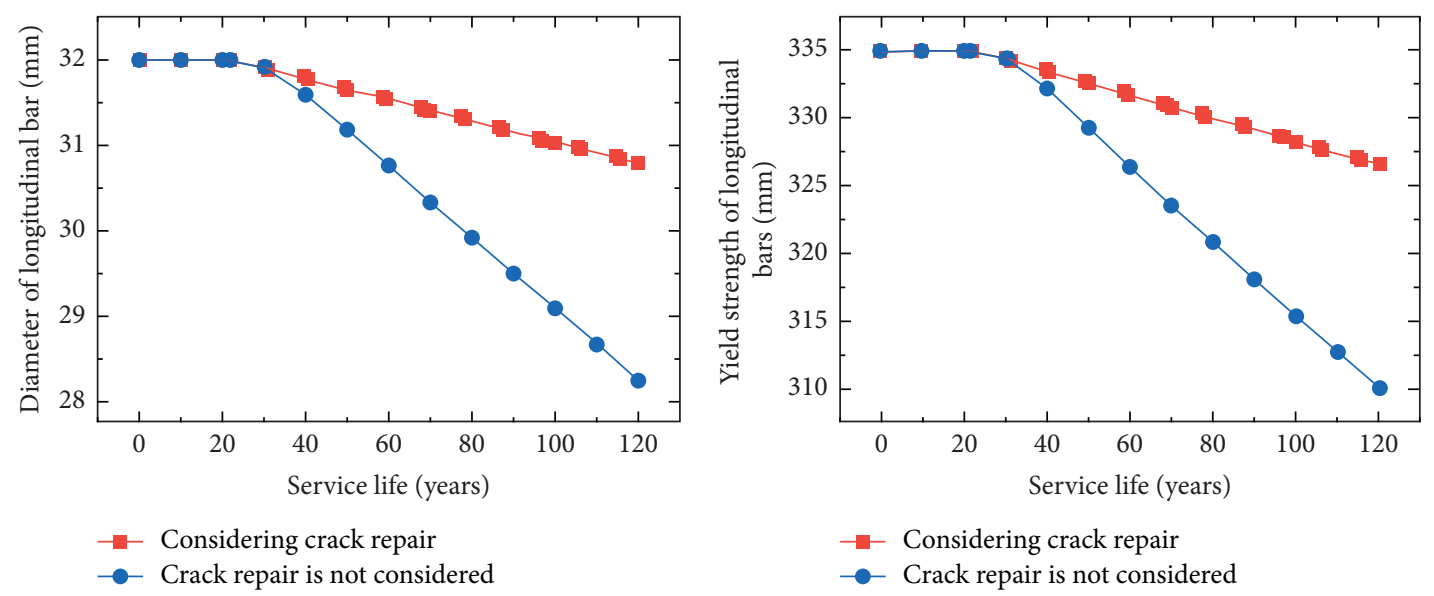

(a)

(b)

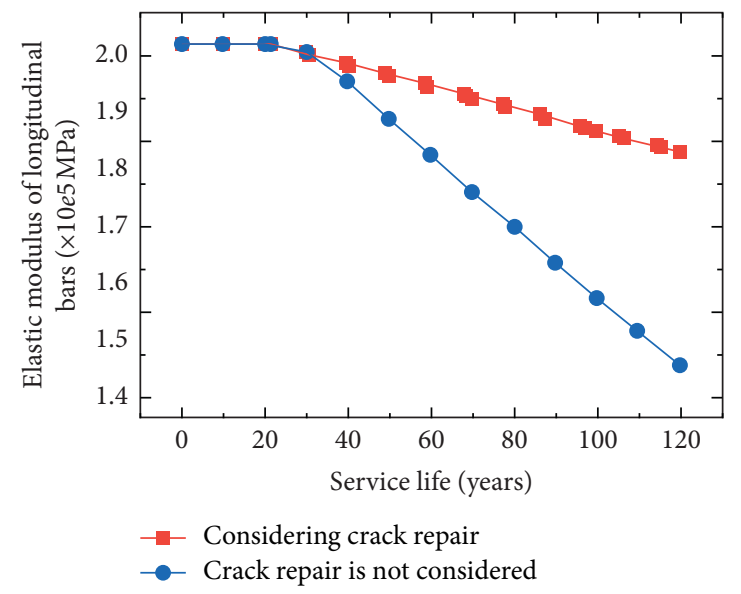

(c)

FIGURE 9: Change in longitudinal steel characteristics: (a) change in diameter; (b) change in yield strength; (c) change in elasticity modulus.

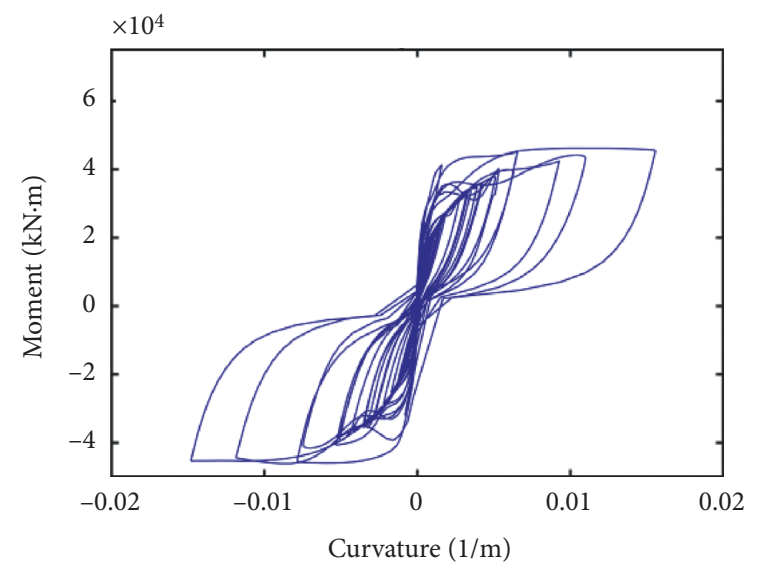

— Damage repair is not considered

Considering damage repair

(a)

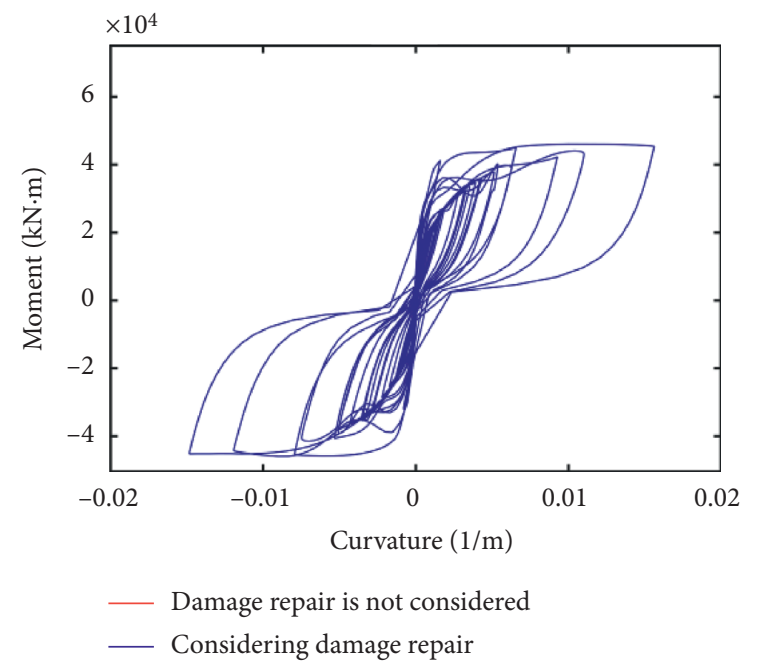

(b)

Figure 10: Continued. 


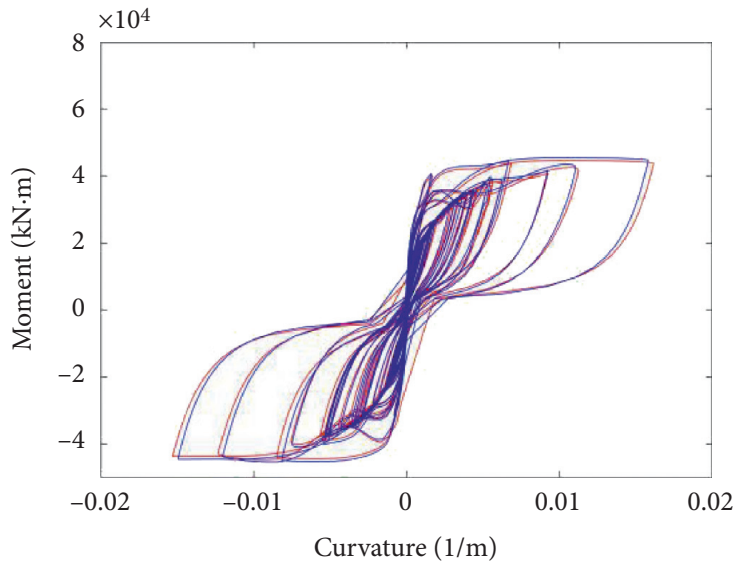

- Damage repair is not considered

_ Considering damage repair

(c)

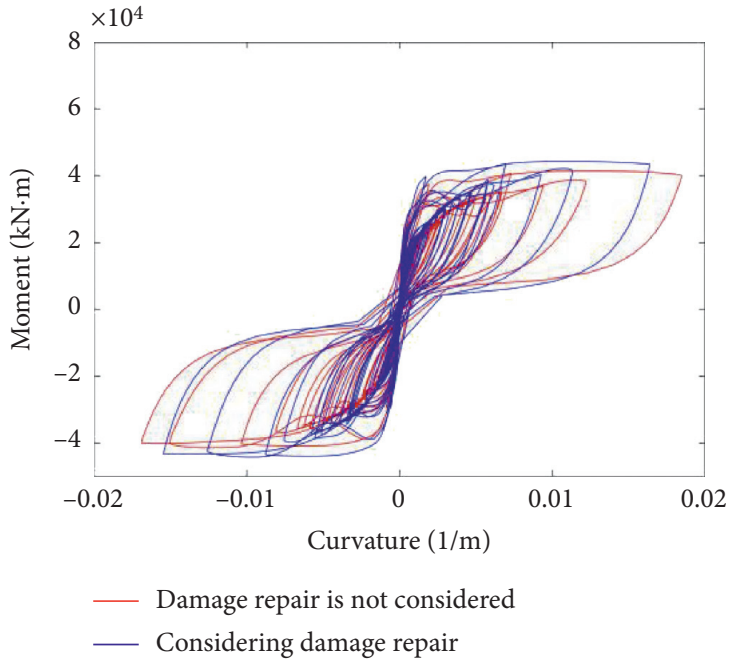

(e)

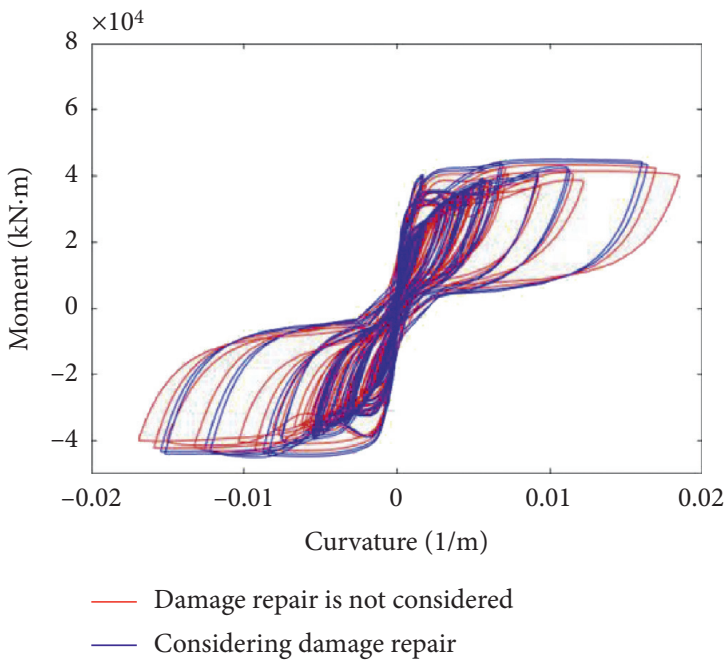

(d)

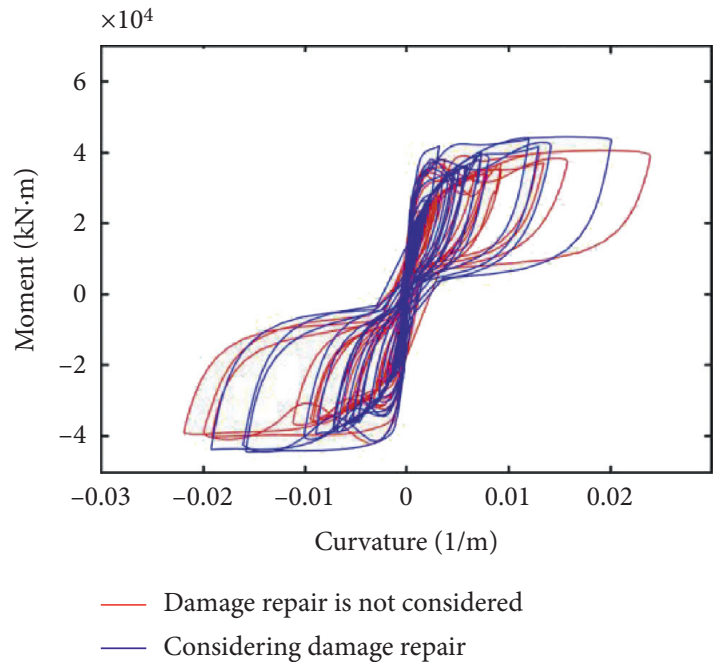

(f)

Figure 10: Moment-curvature curves of the Taiwan wave in different service lifes: (a) 0 years; (b) 30 years; (c) 50 years; (d) 70 years; (e) 100 years; (f) 120 years.

\section{Conclusions}

This study uses the pier of a large-span continuous beam bridge in offshore as the research object. The effects of different seismic action directions, bond slip, and the durability damage repair of materials on the seismic performance of the pier are investigated using OpenSees software. The main research results are summarized as follows:

(1) The corrosion rate of steel bars calculated by different methods is obviously different. In this paper, the more practical CECS method is adopted. According to the calculation method proposed by $\mathrm{Vu}$ and $\mathrm{Du}$, the corrosion rate of steel bars after cracking of concrete cover is greater than that calculated by the CECS 220-2007. There is a certain deviation between the two methods.
(2) Under the simultaneous action of longitudinal and transverse earthquakes, the maximum values of the longitudinal, transverse, and vertical displacements of the Landers wave corresponding to the pier top are $463.8,847.0$, and $38.2 \mathrm{~mm}$, respectively. The transverse displacement of the pier top is considerably larger than the longitudinal and vertical displacements. The transverse seismic response of the high pier deserves attention due to the small transverse stiffness.

(3) When considering the bond slip, the displacement of the pier top is considerably increased. The maximum and minimum displacements are increased by $30.8 \%$ and $14.7 \%$, respectively. The displacement is relatively different. Under the action of the Taiwan wave, the maximum curvature values obtained without 
considering and considering the bond slip are 0.0189 and 0.0156 , respectively. The maximum curvature of the pier is decreased by $17.5 \%$. It shows that when considering the bond slip, the bottom curvature is substantially decreased, and the pinching phenomenon of moment-curvature curve is further evident. Therefore, the influence of the bond slip cannot be ignored in the seismic performance analysis of the bridge.

(4) With the increase in the service life of bridges, the offshore pier suffers increasingly serious concrete carbonation and chloride ion erosion. Considering the durability damage repair of materials, the curvature is increasingly substantially decreased. The maximum curvature can be reduced by $16.0 \%$. After repairing the damage of the pier, the damage of the pier is obviously reduced, which is of great significance for the safety and economy of the pier.

\section{Data Availability}

The data sets used to support the findings of this study are included within the article.

\section{Conflicts of Interest}

The authors declare that there are no conflicts of interest regarding the publication of this paper.

\section{Acknowledgments}

This research was supported by the National Natural Science Foundation of China (Grant no. 51608488) and Scientific and Technological Project of Henan Province, China (192102210185).

\section{References}

[1] S. J. Williamson and L. A. Clark, "Pressure required to cause cover cracking of concrete due to reinforcement corrosion," Magazine of Concrete Research, vol. 52, no. 6, pp. 455-467, 2000.

[2] Y. Tian, J. Liu, H. Xiao et al., "Experimental study on bond performance and damage detection of corroded reinforced concrete specimens," Advances in Civil Engineering, vol. 2020, Article ID 7658623, 15 pages, 2020.

[3] C. A. Apostolopoulos, K. F. Koulouris, and A. C. Apostolopoulos, "Correlation of surface cracks of concrete due to corrosion and bond strength (between steel bar and concrete)," Advances in Civil Engineering, vol. 2019, Article ID 3438743, 12 pages, 2019.

[4] J. H. M. Visser, "Influence of the carbon dioxide concentration on the resistance to carbonation of concrete," Construction and Building Materials, vol. 67, pp. 8-13, 2014.

[5] G. Li, L. Dong, Z. A. Bai, M. Lei, and J. Du, "Predicting carbonation depth for concrete with organic film coatings combined with ageing effects," Construction and Building Materials, vol. 142, pp. 59-65, 2017.

[6] Y. Chen, P. Liu, and Z. Yu, "Effects of environmental factors on concrete carbonation depth and compressive strength," Materials, vol. 11, no. 11, 2018.

[7] D. Baweja, H. Roper, and V. Sirivivatnanon, "Improved electrochemical determinations of chloride-induced steel corrosion in concrete," Materials Journal, vol. 100, pp. 228238, 2003.

[8] S. Morinaga, Prediction of Service Lives of Reinforced Concrete Buildings Based on Rate of Corrosion of Reinforcing Steel, vol. 23, Shimizu Corporation, Tokyo, Japan, 1988.

[9] C. Alonso, C. Andrade, and J. A. González, "Relation between resistivity and corrosion rate of reinforcements in carbonated mortar made with several cement types," Cement and Concrete Research, vol. 18, no. 5, pp. 687-698, 1988.

[10] Z. Ding, Z. Qihui, H. Baohong, Z. Jin, and T. Yuchen, ““Timevarying model" and macroscopic/microcosmic mechanism analysis based on corroded steel mechanical property of bridge durability," Ferroelectrics, vol. 529, no. 1, pp. 128-134, 2018.

[11] I. C. A. Esteves, R. A. Medeiros-Junior, and M. H. F. Medeiros, "NDT for bridges durability assessment on urban-industrial environment in Brazil," International Journal of Building Pathology and Adaptation, vol. 36, no. 5, pp. 500-515, 2018.

[12] M. Raupach, "Investigations on the influence of oxygen on corrosion of steel in concrete-Part 2," Materials and Structures, vol. 29, no. 4, pp. 226-232, 1996.

[13] N. Hearn and J. Aiello, "Effect of mechanical restraint on the rate of corrosion in concrete," Canadian Journal of Civil Engineering, vol. 25, no. 1, pp. 81-86, 1998.

[14] H. Yalciner, S. Sensoy, and O. Eren, “Time-dependent seismic performance assessment of a single-degree-of-freedom frame subject to corrosion," Engineering Failure Analysis, vol. 19, pp. 109-122, 2012.

[15] S. Gadve, A. Mukherjee, and S. N. Malhotra, "Corrosion of steel reinforcements embedded in FRP wrapped concrete," Construction and Building Materials, vol. 23, no. 1, pp. 153-161, 2009.

[16] H.-S. Lee, T. Kage, T. Noguchi, and F. Tomosawa, “An experimental study on the retrofitting effects of reinforced concrete columns damaged by rebar corrosion strengthened with carbon fiber sheets," Cement and Concrete Research, vol. 33, no. 4, pp. 563-570, 2003.

[17] W. Aquino and N. M. Hawkins, "Seismic retrofitting of corroded reinforced concrete columns using carbon composites," Aci Structural Journal, vol. 104, pp. 348-356, 2007.

[18] M. Zhang, R. Liu, Y. Li, and G. Zhao, "Seismic performance of a corroded reinforce concrete frame structure using pushover method," Advances in Civil Engineering, vol. 2018, Article ID 7208031, 12 pages, 2018.

[19] G. Zhao, J. Xu, Y. Li, and M. Zhang, "Numerical analysis of the degradation characteristics of bearing capacity of a corroded reinforced concrete beam," Advances in Civil Engineering, vol. 2018, Article ID 2492350, 10 pages, 2018.

[20] Y. Malecot, L. Daudeville, F. Dupray, C. Poinard, and E. Buzaud, "Strength and damage of concrete under high triaxial loading," European Journal of Environmental and Civil Engineering, vol. 14, no. 6-7, pp. 777-803, 2010.

[21] M. Menegotto, "Method of analysis for cyclically loaded RC plane frames including changes in geometry and non-elastic behavior of elements under combined normal force and bending," in Proceedings of the IABSE Symposium on Resistance and Ultimate Deformability of Structures Acted on by Well Defined Repeated Loads, Lisbon, Portugal, 1973.

[22] N. Shome, C. A. Cornell, P. Bazzurro, and J. E. Carballo, "Earthquakes, records, and nonlinear responses," Earthquake Spectra, vol. 14, no. 3, pp. 469-500, 1998.

[23] International Code Council, International Building Code 2009, Cengage Learning, Boston, MA, USA, 2009.

[24] R. T. Conrad and S. R. C. Winkel, Design Guide to the 1997 Uniform Building Code, John Wiley \& Sons, Hoboken, NJ, USA, 1998. 
[25] American Society of Civil Engineers, Minimum Design Loads for Buildings and Other Structures, American Society of Civil Engineers, Reston, VA, USA, 2006.

[26] B. Wei, C. Li, and X. He, "The applicability of different earthquake intensity measures to the seismic vulnerability of a high-speed railway continuous bridge," International Journal of Civil Engineering, vol. 17, no. 7, pp. 981-997, 2019.

[27] J. E. Padgett, B. G. Nielson, and R. DesRoches, "Selection of optimal intensity measures in probabilistic seismic demand models of highway bridge portfolios," Earthquake Engineering \& Structural Dynamics, vol. 37, no. 5, pp. 711-725, 2008.

[28] N. Xiang and M. S. Alam, "Comparative seismic fragility assessment of an existing isolated continuous bridge retrofitted with different energy dissipation devices," Journal of Bridge Engineering, vol. 24, no. 8, Article ID 4019070, 2019.

[29] S. Shekhar, J. Ghosh, and S. Ghosh, "Impact of design code evolution on failure mechanism and seismic fragility of highway bridge piers," Journal of Bridge Engineering, vol. 25, no. 2, Article ID 4019140, 2020.

[30] S. Misra and J. E. Padgett, "Seismic fragility of railway bridge classes: methods, models, and comparison with the state of the art," Journal of Bridge Engineering, vol. 24, no. 12, Article ID 4019116, 2019.

[31] J. B. Mander, M. J. N. Priestley, and R. Park, "Theoretical stress-strain model for confined concrete," Journal of Structural Engineering, vol. 114, no. 8, pp. 1804-1826, 1988.

[32] D. Niu, Durability and Life Prediction of Concrete Structures, Science Press, Henderson, NV, USA, 2003.

[33] L. Lam, Y. L. Wong, and C. S. Poon, "Degree of hydration and gel/space ratio of high-volume fly ash/cement systems," Cement and Concrete Research, vol. 30, no. 5, pp. 747-756, 2000.

[34] M. Ozaki, A. Okazaki, K. Tomomoto et al., "Improved response factor methods for seismic fragility of reactor building," Nuclear Engineering and Design, vol. 185, no. 2-3, pp. 277-291, 1998.

[35] Y. Liu and R. E. Weyers, "Modeling time-to-corrosion cracking in chloride contaminated reinforced concrete structures," ACI Materials Journal, vol. 96, 1999.

[36] P. J. Missel, "Finite element modeling of diffusion and partitioning in biological systems: the infinite composite medium problem," Annals of Biomedical Engineering, vol. 28, no. 11, pp. 1307-1317, 2000.

[37] W. Wu, L. Li, X. Shao, and S. Hu, "Seismic evaluation of the aged high-pier and long-span bridges subjected to extremely halobiotic condition," in Proceedings of the 7th International Conference on Bridge Maintenance, Safety and Management, Shanghai, China, 2014.

[38] K. A. T. Vu and M. G. Stewart, "Structural reliability of concrete bridges including improved chloride-induced corrosion models," Structural Safety, vol. 22, no. 4, pp. 313-333, 2000.

[39] Y. G. Du, L. A. Clark, and A. H. C. Chan, "Residual capacity of corroded reinforcing bars," Magazine of Concrete Research, vol. 57, no. 3, pp. 135-147, 2005.

[40] Architecture and Building Press, Standard for Durability Assessment of Concrete Structures (CECS220-2007), Architecture \& Building Press, Beijing, China, 2007.

[41] S. Mazzoni, F. McKenna, M. H. Scott, and G. L. Fenves, OpenSees Command Language Manual, vol. 264, Pacific Earthquake Engineering Research (PEER) Center, Berkeley, CA, USA, 2006.

[42] T. Vidal, A. Castel, and R. François, "Analyzing crack width to predict corrosion in reinforced concrete," Cement and Concrete Research, vol. 34, no. 1, pp. 165-174, 2004. 